[Agr. Biol. Chem., Vol. 35, No. 12, p. 1870 1879, 1971]

\title{
Identification of Hydroxybenzylamines in Buckwheat Seeds (Fagopyrum esculentum Moench)
}

\author{
By Masahiro Koyama, Yataro Obata and Sadao Sakamura \\ Department of Agricultural Chemistry, Faculty of Agriculture, \\ Hokkaido University, Sapporo, Japan \\ Received May 17, 1971
}

\begin{abstract}
The first isolation of naturally occurring salicylamine and its Schiff base, 2-hydroxy-N$\left(2^{\prime}\right.$-hydroxybenzylidene)-benzylamine and the co-existence of free 4-hydroxybenzylamine in the achenes of Fagopyrum esculentum Moench which are commonly used as human food in Japan, have been described.

The structural confirmation of these compounds as carried out on the basis of the elementary analyses and spectroscopic properties and, eventually, by comparison with authentic specimens, if necessary.
\end{abstract}

During an investigation of non-protein amino acid fraction of buckwheat seeds, several unusual spots, giving rise to a yellow color with ninhydrin which subsequently turn purple on paper chromatogram, were observed. Furthermore, their behaviour on ion-exchange resins is suggestive of basic amphoterites and amines. The two major constituents of these basic substances have now been isolated in the crystalline state from aqueous alcoholic extracts of buckwheat seeds and their structures were established as salicylamine and 4hydroxybenzylamine, respectively. It was also observed that the hydroxybenzylamines are subject to autoxidation with presumable formation of polymers in various stages. On the crystallization of sublimates of the hydroxybenzylamines from absolute ethanol and petroleum ether, the mother liquor of 4hydroxybenzylamine produced brown colored oily residue which progressively turned darkred or -brown amorphous precipitates in aqueous alcoholic solution, being allowed to stand for some time in contact with air. In the case of the isolated salicylamine fraction, the yellowish brown residue on sublimation gave yellow needles, after crystallization from ethanol or chloroform, which fluoresced a light yellow color on exposure to ultraviolet light. The resulting crystals which possessed the elementary composition $\mathrm{C}_{14} \mathrm{H}_{13} \mathrm{NO}_{2}$, was characterized as a Schiff base of salicylamine, 2-hydroxy-N-( $2^{\prime}$ - hydroxybenzylidene)-benzylamine on the basis of its spectroscopic properties. While the free hydroxybenzylamine in higher plants has previously been encountered only in seeds of Sinapis alba L.," the naturally occurring salicylamine and its Schiff base have been isolated for the first time from achenes of Fagopyrum esculentum Moench which are commonly consumed as human food in Japan.

\section{EXPERIMENTAL AND RESULTS}

\section{Isolation}

Commercially available buckwheat seeds $(45 \mathrm{~kg})$ were pulverized and extracted repeatedly with $70 \%$ ethanol at ambient temperature. The clear extracts were passed through an Amberlite IR-120B (4 liters, $\mathrm{H}^{+}$)

1) P. Olesen Larsen, Biochim. Biophys. Acta, 107, 134 (1965). 
column pre-equilibrated with $70 \%$ ethanol. After washing the column throughly with $70 \%$ ethanol and desalted water, successively, the crude amino acid fraction was obtained by elution from the column with $2 \mathrm{~N} \mathrm{NH}_{4} \mathrm{OH}$, followed by evaporation to dryness in vacuo at $40^{\circ} \mathrm{C}$. The residue was dissolved in a minimum volume of desalted water and adjusted to $\mathrm{pH} 4.0$ with glacial acetic acid. The turbid solution was allowed to stand overnight in a refrigerator and filtered from the resulting muddy precipitate. The filtrate was then put through a $8 \times 53 \mathrm{~cm}$ column of Dowex $1 \mathrm{X}-4\left(\mathrm{AcO}^{-}, 200 \sim 400 \mathrm{mesh}\right)$ and washed with desalted water until the effluent was no longer positive with ninhydrin. The combined effluent containing neutral and basic amino acids together with amines, were concentrated to a small volume and applied to a Dowex 50W X-4 column (mesh 200 400, 5.6 $x 86 \mathrm{~cm}$, ammonium type). After adequate washing with water to remove neutral amino acids from the column, basic amino acids and amines by a stepwise elution with 0.1 to $0.5 \mathrm{~N}$ $\mathrm{NH}_{4} \mathrm{OH}$ were fractionated, 1310 fractions of $43.7 \mathrm{ml}$ each being collected at flow rate of $2.5 \mathrm{ml}$ per min. Elution was first with $0.1 \mathrm{~N}$ $\mathrm{NH}_{4} \mathrm{OH}$ and the concentration of ammonia was increased to $0.2 \mathrm{~N}$ at fraction 435 , to $0.5 \mathrm{~N}$ at 904 , respectively. Ninhydrin positive substances were detected in each fraction by onedimensional ascending chromatography on Toyo Roshi No. 50 paper using $n$-butanolacetic acid-water (4:1:5, upper layer) as a solvent system.

Fractions 591 741 contained the unknown compound (called thereafter as FYS-1) with $R f$ value of 0.58 in the above solvent (BAW), showing a yellow ninhydrin reaction. When uncontaminated fractions 591 693 of FYS-1, were combined and evaporated to dryness in vacuo at $40^{\circ} \mathrm{C}$, the yellowish brown residue was obtained besides the crystals sublimated at the neck of the flask. The colourless fine needles scraped from the flask was indistinguishable from FYS-1 on paper chromato- grams. The residue was then transferred to Mills sublimation flask and heated at bath temperature of 55 to $75^{\circ} \mathrm{C}$ under a reduced pressure of $0.1 \mathrm{mmHg}$ for $4 \mathrm{hr}$. The pale yellow sublimates were recrystallized from absolute ethanol and petroleum ether. The combined fractions $694 \sim 711$ which contained a small amount of arginine as a contaminant, were worked up in a similar manner as above and the overall yield of the colourless needles of FYS-1 was $2.65 \mathrm{~g}$. The brown residue on sublimation was dissolved in absolute ethanol and filtered. The clear solution became turbid on addition of water, and gave yellow needles which fluoresced a light yellow color under ultraviolet light. Additional crops of the compound, termed FCS, was also obtained from FYS-1 fraction before sublimation.

Another ninhydrin-yellow spot (FYS-2), Rf 0.50 in BAW system, appeared in fractions between 712 and 820 together with FYS-1, containing arginine and others as contaminants. Combined fractions were evaporated to dryness below $40^{\circ} \mathrm{C}$ in vacuo and dissolved in BAW. Aliquots of the solution were applied to a $8.2 \times 30 \mathrm{~cm}$ column of Whatman column chromedia CF 11 in BAW and chromatographed by using the same solvent for developing. The fractions containing only FYS-2 were collected and evaporation of the solution left a crystalline brown residue. Sublimate of the residue at a bath temperature of $100^{\circ} \mathrm{C}$ at $0.005 \mathrm{mmHg}$ was recrystallized from absolute ethanol and petroleum ether to give $137 \mathrm{mg}$ of colorless columnar crystals of FYS-2.

\section{Properties and structural elucidation}

Slender needles of FYS-1 melted at $127 \sim 8^{\circ} \mathrm{G}$, showing yellow color, in a sealed tube and possessed the elementary composition $\mathrm{C}_{7} \mathrm{H}_{9} \mathrm{NO}$ by elemental analysis and mass spectrometry $\left(\mathrm{M}^{+}\right.$, m/e: 123): Anal. Found: $\mathrm{C}, 68.18 ; \mathrm{H}$, 7.44; $\mathrm{N}, 11.59$. Calcd. for $\mathrm{G}_{7} \mathrm{H}_{9} \mathrm{NO}$ (MW 123): $\mathrm{C}, 68.27 ; \mathrm{H}, 7.37 ; \mathrm{N}, 11.37 \% 6$. Its $R f$ value was 0.58 in $\mathrm{BAW}, 0.65$ in tert-BuOH- 
$\mathrm{HCOOH}-\mathrm{H}_{2} \mathrm{O}(75: 15: 15), 0.72$ in both tert$\mathrm{BuOH}-n-\mathrm{BuOH}-2 \mathrm{~N}-\mathrm{NH}_{4} \mathrm{OH} \quad(2: 5: 7)$ and isopropanol-28\% $\mathrm{NH}_{4} \mathrm{OH}-\mathrm{H}_{2} \mathrm{O} \quad(8: 1: 1)$, respectively. On paper chromatograms

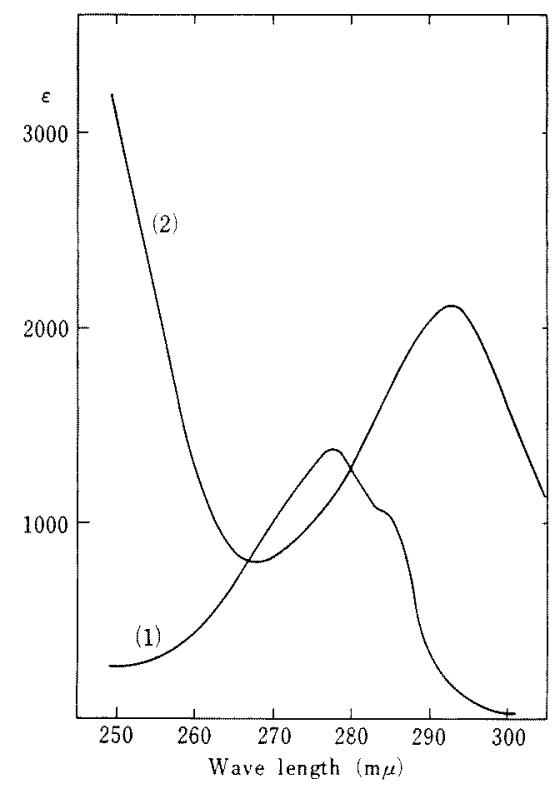

FIG. 1. UV Spectra of FYS-1 in $\mathrm{EtOH}(1)$ and Alc. $0.1 \mathrm{~N} \mathrm{NaOH}(2)$. sprayed with $0.1 \%$ ninhydrin in $95 \%$ alcohol and heated at $90^{\circ} \mathrm{C}$ for $5 \mathrm{~min}$, it gave yellow color which gradually became brown and finally purple on standing at room temperature. This change which takes place more rapidly in FYS-2 than in FYS-1 was most

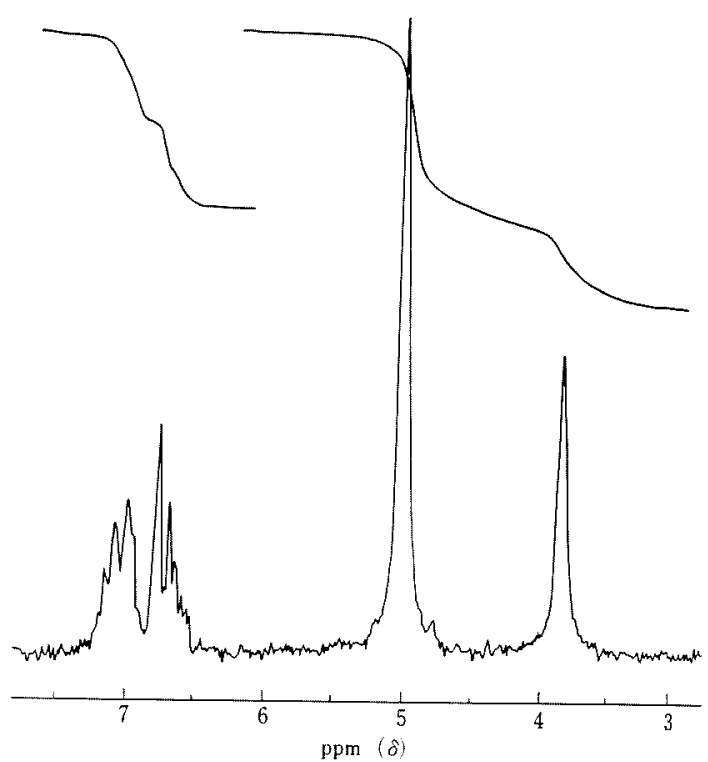

FIG. 3. $60 \mathrm{MHz}$ Spectrum (ód DMSO-d $_{6}$ ) of FYS-1.

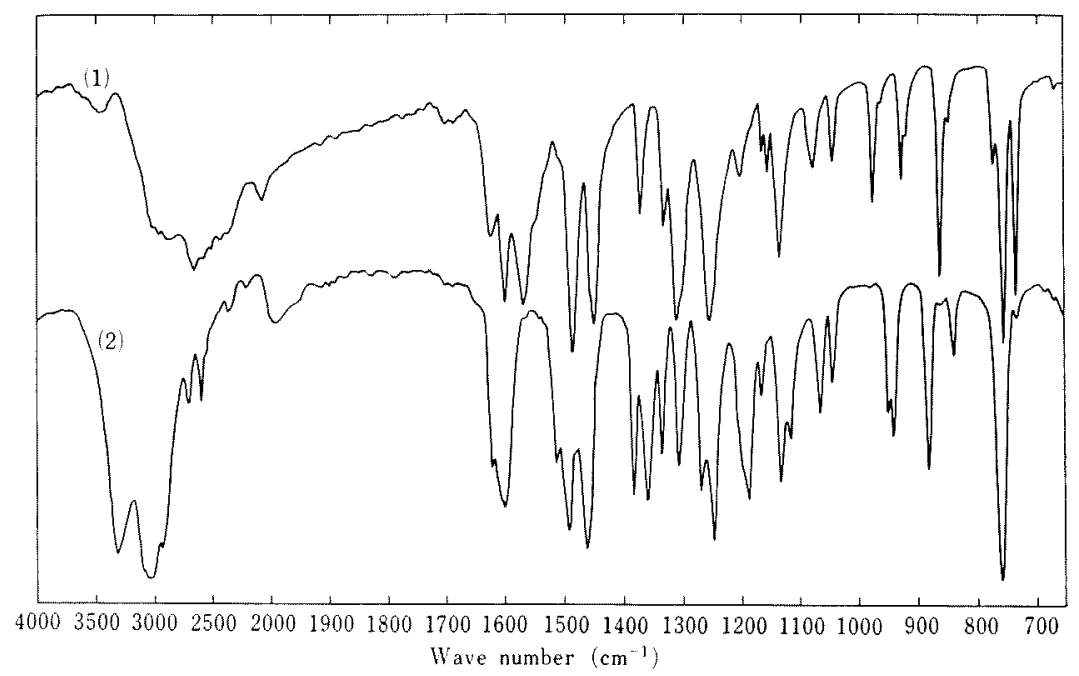

FIG. 2. IR Spectra of FYS-1(1) and its Hydrochloride (2) (KBr). 
characteristic and was probably due to the effect of atmospheric moisture, since it was inhibited by cooling the paper in a desiccator. FYS-1 did not react with isatin but gave a blue color with Folin-Giocalteu reagent for phenols, ${ }^{2}$ as FIS-2 did. The behavior of the ninhydrin-yellow substances in buckwheat seeds is very similar to that of benzylamine type compounds."

The ultraviolet absorption spectrum of FYS-1 (Fig. 1) indicated that the molecule contained a conjugated system. The bathochromic shift of the absorption maximum at $276 \mathrm{~m} \mu$ toward $295 \mathrm{~m} \mu$ in alkaline solution suggested that the compound could be a phenol derivative. The infrared spectrum of FYS-1 (Fig. 2) showed absorption bands at $2700 \sim 2000,1620,1565$ and $1310 \mathrm{~cm}^{-1}$, typical for a zwitterionic amino acid structure, but its hydrochloride $\left(\mathrm{C}_{7} \mathrm{H}_{9} \mathrm{NO} \cdot \mathrm{HCl}, \mathrm{mp} 147 \sim 8^{\circ} \mathrm{C}\right)$ indicated the absence of carboxyl group absorption. $^{4,5)}$ In addition, peaks at 1600 ,

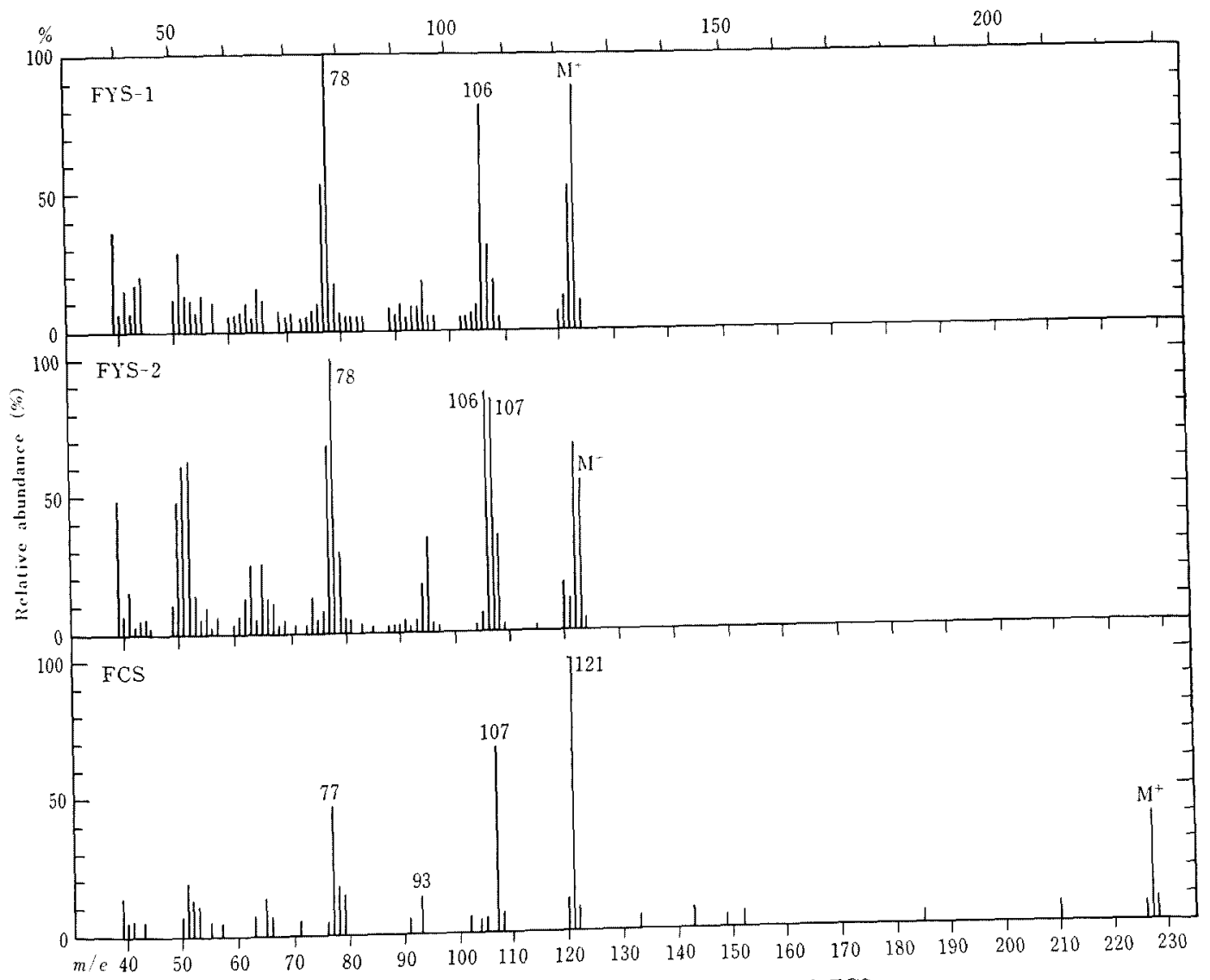

FIG. 4. Mass Spectra of FYS-1, FYS-2 and FCS.

2) O. Folin and V. Ciocalteu, J. Biol. Chem., 73, 627 (1927).

3) M. Sawai, E. Takagi, M. Mangyo and I. Ensaka, J. Chem. Soc. Japan, 76, 259 (1955); Bull. Chem. Soc. Japan, 28, 213 (1955).
4) L. J. Bellamy, "The Infra-red Spectra of Complex Molecules," New York, N. Y., 1958, pp. 234.

5) J. P. Greenstein and M. Winitz, "Chemistry of the Amino Acids," Vol. II, John Wiley and Sons, Inc., New York, 1961, pp. 1965. 
$1485 \mathrm{~cm}^{-1}$ and a strong band at $755 \mathrm{~cm}^{-1}$, together with the complex absorptions centered at $\delta: 6.85 \mathrm{ppm}(4 \mathrm{H})$ in NMR spectrum (Fig. 3), prognosticated the presence of an unsymmetrically 1,2-disubstituted benzene ring in FYS-1. The NMR spectrum also showed a sharp singlet at $\delta: 5.00 \mathrm{ppm}$ due to three exchangeable protons, as might be expected for the combined resonance of an $\mathrm{OH}$ and a $\mathrm{NH}_{2}$-proton. The remaining two protons in the molecule resonate as a two-proton singlet at $3.84 \mathrm{ppm}$ which could be assigned to a methylene proton of a benzylamine function. Data presented so far suggest 2-hydroxybenzylamine (salicylamine) structure for FYS-1. This structure recieves reasonable support from the result of mass spectrometry. In the isolated salicylamine (Fig. 4), the most prominent fragmentation process involves the successive elimination of ammonia ( $m / e: 106)$ and carbon monoxide (base peak at $m / e ; 78$ ), as demonstrated by a resemblance to the mechanism of 2-hydroxybenzyl alcohol comprised of loss of water instead of ammonia. ${ }^{6}$ Final proof of the structure was obtained by comparison of FYS-1 with authentic specimen which was prepared from salicylamide by reduction with LiAlH $_{4}{ }^{71}$ Chemical and physical properties of FYS-1 were fully identical to those of salicylamine.

Analytical data and the molecular ion $\left(\mathrm{M}^{+}\right.$, m/e: 123) of FYS-2, melted at $113 \sim 4^{\circ} \mathrm{C}$ in a sealed tube, are compatible only with a molecular formula $\mathrm{C}_{7} \mathrm{H}_{9} \mathrm{NO}$ : Anal. C, 67.75; $\mathrm{H}, 7.33 ; \mathrm{N}$, 11.18. Calcd. for $\mathrm{C}_{7} \mathrm{H}_{9} \mathrm{NO} ; \mathrm{C}$,

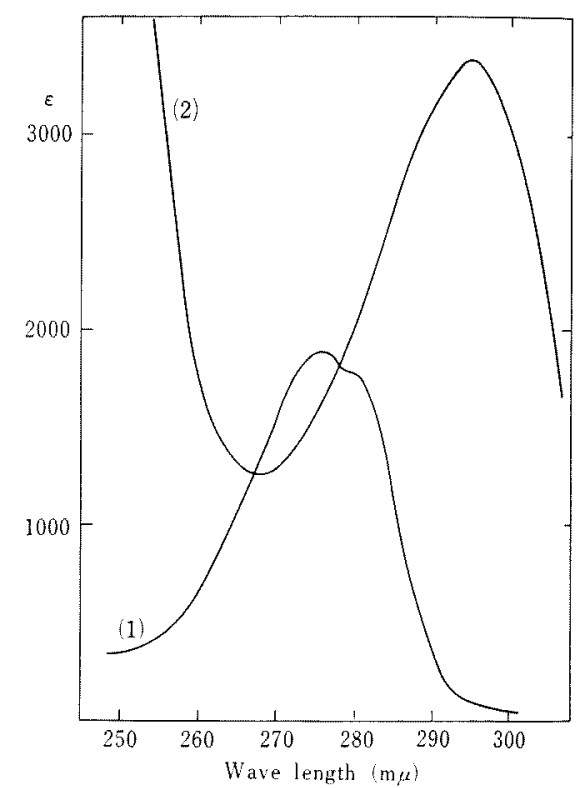

FIG. 5. UV Spectra of FYS-2 in $\operatorname{EtOH}(1)$ and Alc. $0.1 \mathrm{~N} \mathrm{NaOH}(2)$.

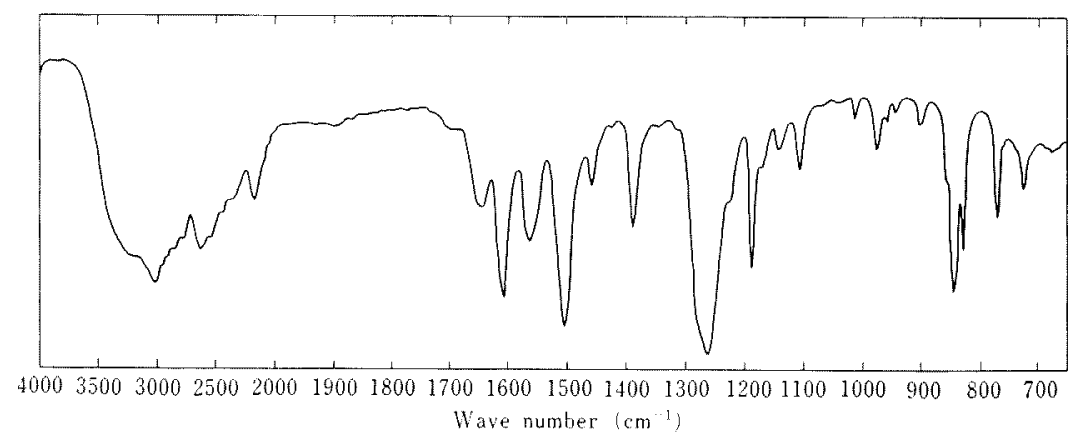

FIG. 6. IR Spectrum of FIS-2 (KBr).

6) H. Bukzikiewicz, C. Djerassi and D.H. Williams, "Mass spectrometry of Organic compounds," HoldenDay, Inc., San Francisco, Calif., 1967, pp. 121.
7) H. E. Zaugg and D. Schaeffer, J. Org. Chem., 28, 2925 (1963). 
$68.27 ; \mathrm{H}, 7.37 ; \mathrm{N}, 11.37 \%$. Rf values of the compound in several solvent systems were as follows; 0.50 in $\mathrm{BAW}, 0.60$ in tert $-\mathrm{BuOH}-\mathrm{HCO}_{2} \mathrm{H}-\mathrm{H}_{2} \mathrm{O}$ $(75: 15: 15), 0.62$ in tert-BuOH- $n-\mathrm{BuOH}-2 \mathrm{~N}-$ $\mathrm{NH}_{4} \mathrm{OH}(2: 5: 7)$, and 0.67 in isopropanol-28, $\mathrm{NH}_{4} \mathrm{OH}-\mathrm{H}_{2} \mathrm{O}(8: 1: 1)$. The elemental composition, together with the remarkable similarity of the ultraviolet absorption characteristics (Fig. 5) of FYS-1 and FYS-2 clearly reveals that the compounds are isomers. The infra-red spectrum (Fig. 6) also suggested the presence of amino and phenol groups in the molecule. On the basis of the strong band at $842 \mathrm{~cm}^{-1}$

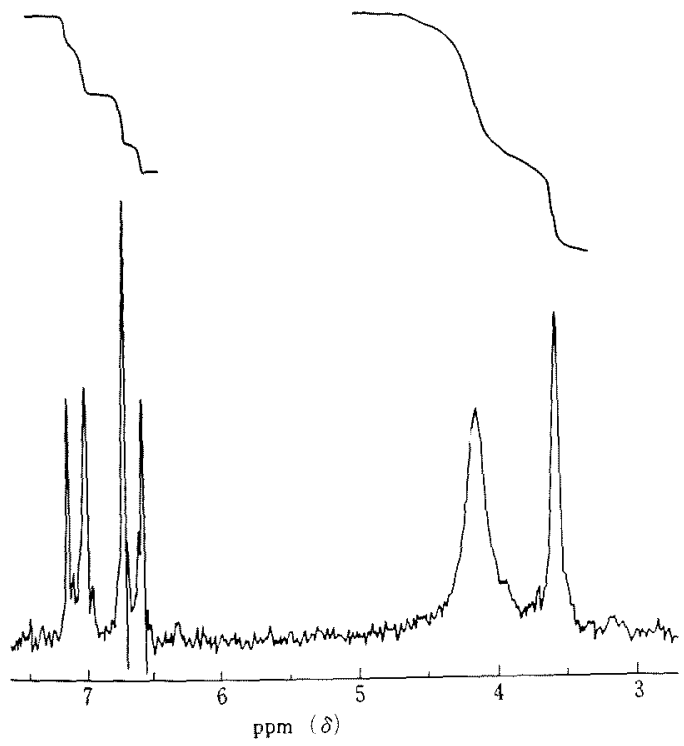

FIG. 7. $60 \mathrm{MHz}$ spectrum (ôMSO-de TMS $_{e}$ ) FXS-2. and the splitting pattern of the NMR signals centered at $\delta: 6.85 \mathrm{ppm}$ equivalent to four aromatic protons (Fig. 7), the presence of a 1, 4disubstituted benzene structure was deduced. The broad singlet at $4.15 \mathrm{ppm}$ due to three protons eliminated by shaking with $\mathrm{D}_{2} \mathrm{O}$ was assigned to a phenolic $\mathrm{OH}$ and amine protons and the two-proton singlet at $3.58 \mathrm{ppm}$ was ascribed to the isolated methylene protons just the same as those of FYS-1. A conspicuous feature of the mass spectrum of FYS-2 (Fig. 4) is rather high intensity of fragment peak at $m / e: 107 \quad\left[4-\mathrm{HO}-\mathrm{C}_{6} \mathrm{H}_{4} \mathrm{CH}_{2}\right]^{+}$which would result from resonance stabilization with contribution of the hydroxy group in the para position. ${ }^{51}$ These data and direct comparison with an authentic sample prepared from 4hydroxybenzamide ${ }^{61}$ confirmed 4-hydroxybenzylamine structure for FYS-2.

The yellow crystal of FCS ( $\mathrm{mp} 185 \sim 7^{\circ} \mathrm{C}$ ) which fluoresces a light yellow color under ultraviolet light, possessed the elementary composition, $\mathrm{C}_{14} \mathrm{H}_{13} \mathrm{NO}_{2}$ : Anal. found: $\mathrm{C}, 73.84$; $\mathrm{H}, 5.70 ; \mathrm{N}, 6.33$. Calcd. for $\mathrm{C}_{14} \mathrm{H}_{13} \mathrm{NO}_{2}: \mathrm{C}$, 73.99; H, 5.77; N, 6.160: $\mathrm{M}^{+}$, m/e: 227. On paper chromatography in the acidic solvent systems its yellow color and fluorescence faded out during development and salicylamine was detected alone. Upon development in the ammoniacal solvent systems, it gave a considerably elongated spot of which the tail end migrated at the same rate of salicylamine on paper, changing the color into yellow brown at the head of a spot. Thin-layer chromato-

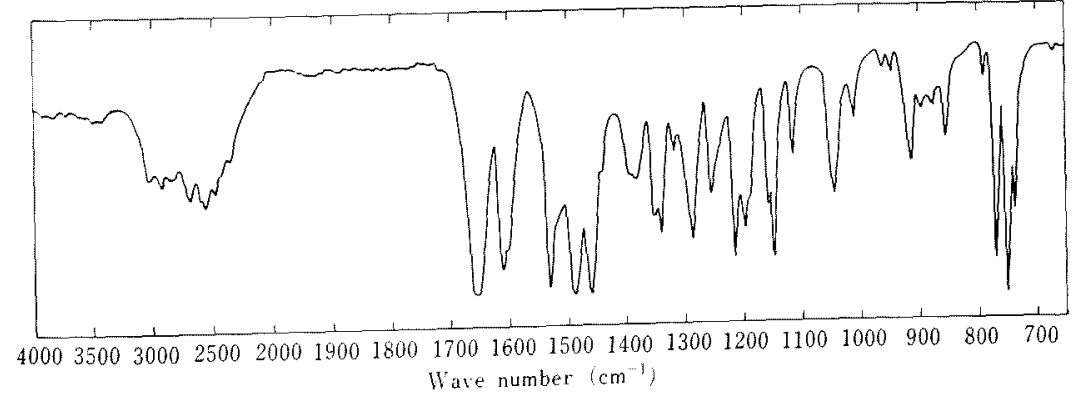

FIG. 8. IR Spectrum of FCS (KBr). 


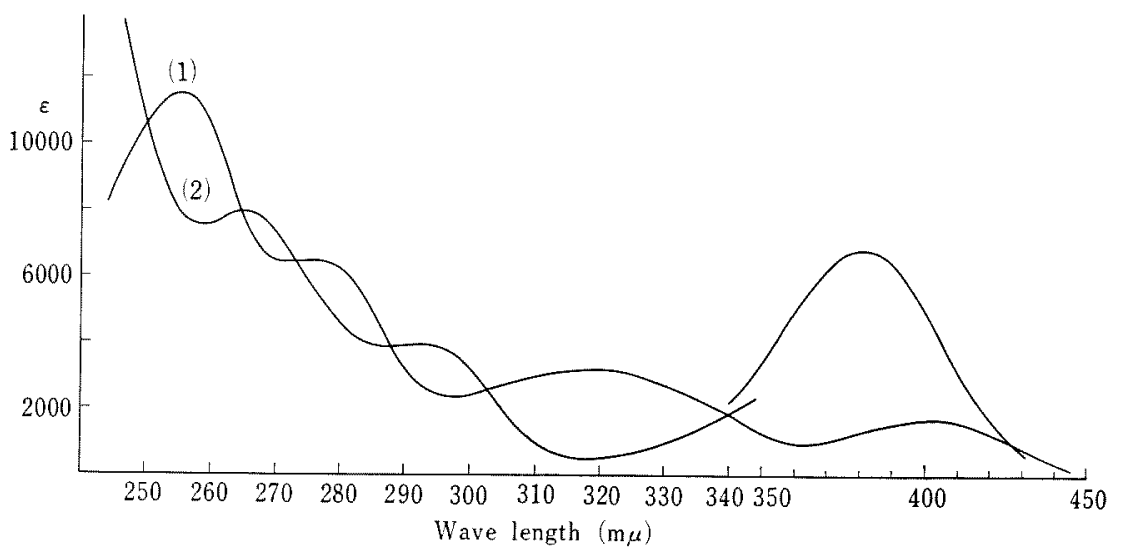

FIG. 9. UV Spectra of FCS in $80 \% \mathrm{EtOH}(1)$ and in Alc. $0.1 \mathrm{~N} \mathrm{NaOH}(2)$.

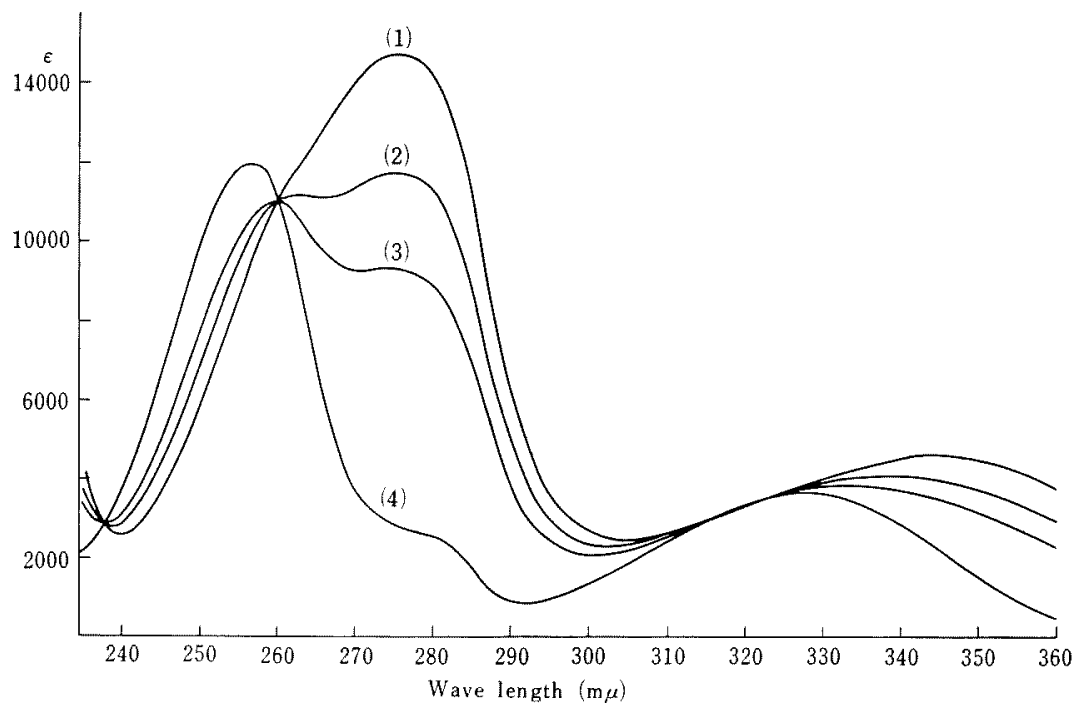

- FIG. 10. Spectral Changes of FCS in $0.1 \mathrm{~N} \mathrm{HCl} / 800^{\circ} \mathrm{EtOH}:$ (1) within $2 \mathrm{~min}$, (2) after $30 \mathrm{~min},(3) 1 \mathrm{hr}$ and (4) $6 \mathrm{hr}$.

graphy on WAKOGEL B-5 using chloroformmethanol $(20: 1)$ as the solvent revealed a single yellow and yellow fluorescent spot with an $R f$ value of 0.54 ; and $R f$ value of salicylamine was 0.03 under the same conditions.

The characteristic absorption bands in the infrared region (Fig. 8) were observed at $2700 \sim 2550 \mathrm{~cm}^{-1}$ (strongly hydrogen bonded $\mathrm{OH}$ stretching), $1655 \quad(\mathrm{C}=\mathrm{N}), \quad 1287 \mathrm{~cm}^{-1}$ (phenolic C-O) $)^{8 \sim 10 \prime}$ and 3030, 1610, 1599, 1490, $750 \mathrm{~cm}^{-1}$ (1, 2-disubstituted benzene). The UV spectrum of FCS in $80 \%$ EtOH solution (Fig. 9) showed absorption maxima at 256, 276, 319 8) H. H. Ereedman, J. Am. Chem. Soc., 83, 2900 (1961).

9) S. Inouye, Chem. Pharm. Bull. (Tokyo), 15, 1540 (1967).

10) J.E. Kovacic, Spectrochim. Acta, 23A, 183 (1967). 


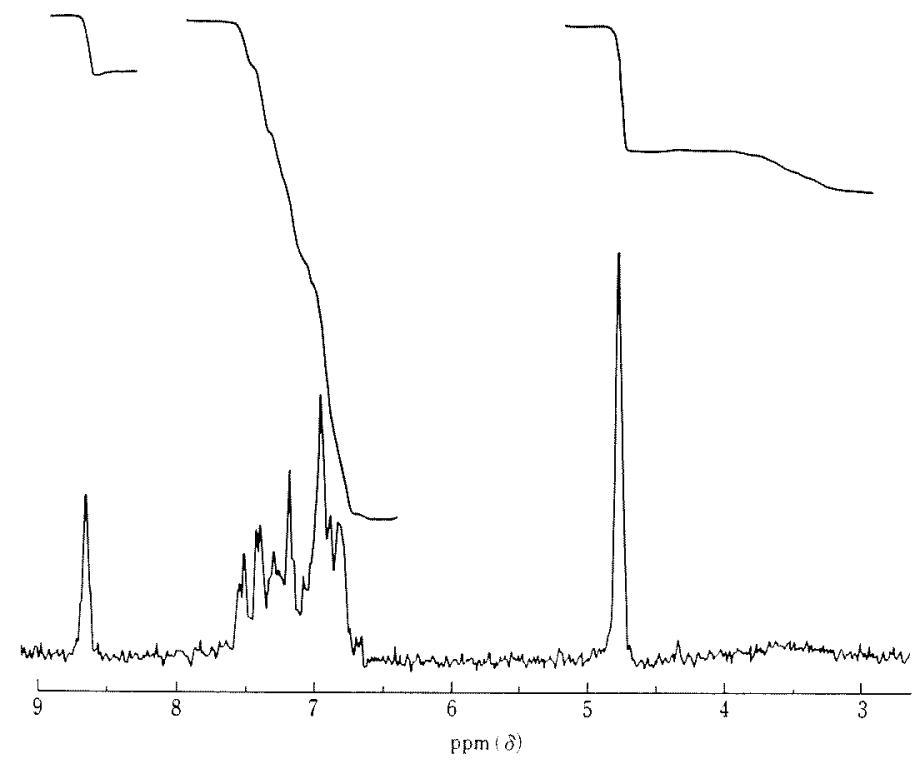

FIG. 11. $60 \mathrm{MHz}$ Spectrum (ón $\left.{ }_{\mathrm{DMSO}-\mathrm{d}_{\theta}}^{\text {TMS }}\right)$ of FCS.

and $403 \mathrm{~m} \mu$, corresponding to bands for the Schiff base derived from salicylaldehyde and amines. $^{9-11)}$ In ethanolic $\mathrm{N} / 10 \mathrm{HCl}(80 \%$ EtOH), the UV absorption maxima initially changed to $277,348 \mathrm{~m} \mu$, followed by a further modification in function of the time occurred with isosbestic points at 238, 260, $313 \mathrm{~m} \mu$, owing to the hydrolysis of the Schiff base and, after $6 \mathrm{hr}$, the spectrum became almost identical with the one of the equimolar mixture of salicylaldehyde $(256,328 \mathrm{~m} \mu)$ and salicylamine $(277 \mathrm{~m} \mu)$ (Fig. 10). The spectrum in ethanolic $\mathrm{N} / 10 \mathrm{NaOH}(80 \% \mathrm{EtOH}$ ) (Fig. 9), however, immediately showed the peaks at 265,381 and $295 \mathrm{~m} \mu$, corresponding to those of salicyl-aldehyde and -amine, respectively, and no change of peaks was observed over a $24 \mathrm{hr}$ period.

NMR spectrum of the compound (Fig. 11) showed a complex multiplet centered at approx. $7.10 \mathrm{ppm}$ due to protons, of which one proton was removed by shaking with

11) J. Charette, G. Falthansl and Ph. Teyssie, Spectrochim. Acta, 20, 597 (1964).
$\mathrm{D}_{2} \mathrm{O}$, obviously revealing the presence of the phenolic proton hidden under the aromatic resonances. An additional exchangeable phenolic proton resonated as a remarkably broad, flat absorption centered at approx. $\delta$ : $3.50 \mathrm{ppm}$. The two singlets at $\delta: 8.65 \mathrm{ppm}$ due to one proton and $\delta: 4.76 \mathrm{ppm}$ accounted for two protons can be assigned to the azomethine proton and the benzylic methylene attached to a nitrogen atom in $\mathrm{C}=\mathrm{N}$ group, respectively, in good agreement with the relative chemical sifts previously observed in similar system. ${ }^{12,131}$ The data described so far are consistent with a formulation of the fluorescent compound as 2-hydroxy-N-( $2^{\prime}$ hydroxybenzylidene)-benzylamine, a Schiff base of salicylamine. Furthermore, this conclusion is fully supported by the appearance of following prominent fragments in mass spectrum (Fig. 4); a strong peak at $\mathrm{m} / \mathrm{e} 121$ reasonably represents the ion $\left[\mathrm{HO}-\mathrm{C}_{6} \mathrm{H}_{4}-\mathrm{CH}=\right.$

12) A.F. McDonagh and H. E. Smith, Chem. Comm., 1966 (12), 374.

13) N. M. D. Brown and D. C. Nonhebel, Tetrahedron, 24, 5655 (1968). 
$\mathrm{NH}]^{+}$formed by cleavage of the $\mathrm{N}-\mathrm{CH}_{2}$ bond with rearrangement of one hydrogen atom, whereas salicylidene-2-hydroxy-aniline, so-called nor-Schiff base, gave the intense peak at $m / e, 120$ due to the protonated benzoxazole or benzisoxazole structure. ${ }^{14}$ Two peaks at $m / e 107$ and 93 resulted from $\alpha$-fission at both sides of $\mathrm{N}=\mathrm{CH}$ group are preferably assigned to the $\left[\mathrm{HO}-\mathrm{C}_{6} \mathrm{H}_{4}-\mathrm{CH}_{2}\right]$ and the $\left[\mathrm{HO}-\mathrm{C}_{6} \mathrm{H}_{4}\right]$ cations, respectively. Direct loss of the hydroxyl group from the molecular ion $(\mathrm{m} / \mathrm{e}$ 210 ) is also observed to a larger extent than in the nor-isomer itself. ${ }^{14}$

\section{DISCUSSION}

As in the results described above, salicylamine, 4-hydroxybenzylamine and $\mathrm{N}$ salicyliden-salicylamine have been isolated from the non-protein amino acid fraction of buckwheat seeds and unequivocally characterized. Although many phenolic amines are found in most animals and plants, ${ }^{15-17}$ the occurrence of free benzylamines in nature have rarely been observed. Thus free 4hydroxybenzylamine of natural derivation have previously been encountered in white mustard (Sinapis alba L.) ${ }^{11}$ and in human urine that may be extracted after the ingestion of the seasoning. ${ }^{18)}$ It is of interest that the flesh bark of horse radish tree (Moringa pterygosperma Gaertn) used as a pungent flavoring, contains free benzylamine. ${ }^{191}$ P. O. Larsen has discussed to some extent on a biogenetic relationship between thioglucosides and free

14) D. J. Elias and R. G. Gills, Aust. J. Chem., 19, 251 (1966).

15) "Biochemistry of Phenolic Compounds," ed. by J. B. Harbome, Academic Press Inc., London, 1964 , p. 273.

16) J.M. Foy and J.R. Paratt, J. Pharm. Pharmacol, 13, 382 (1961).

17) K. P. Bhargava, K. Kihor, M. C. Pant and P. R. Saxena, Brit. J. Pharmacol., 25, 743 (1965).

18) Y. Kakimoto and M. D. Armstrong, J. Biol. Chem., 237, 208 (1962).

19) R. N. Chakravarti, Bull. Calcutta School Trop. Med., 3, 162 (1955) [C.A., 50, 1689le (1960)]. amines presented together in several plants. ${ }^{1,20}$ While Polygonum hydropiper L. and its varieties, being classified into the same family (Polygonaseae) as buckwheat, are also consumed as hot spices in Japan, their pungent principles have already been shown to be sesquiterpene aldehydes $^{21-23)}$ and a similar relationship has never been imagined so far in buckwheat which contains free salicylamine, not previously isolated as a natural products.

S. Seto et al. have demonstrated that both 2- and 4-hydroxybenzylamine play an important role as initial intermediates in "Amoniak-Resol" production and salicylamine in aqueous alcohol easily changed to the Schiff base by condensation with salicylaldehyde produced by air oxidation and subsequent hydrolysis of salicylamine itself. ${ }^{241}$ Therefore, it may be concluded that the isolated Schiff based arised as an artifact from salicylamine during purification. In addition, it was actually observed that hydroxybenzylamines, particularly 4-hydroxybenzylamine, are ready to take straw color on the crystallization from suitable solvents, progressively affording red-brown tarry or amorphous residue which markedly interfere with the crystallization. Thus it may be conceivable that the oxidative change of hydroxybenzylamines to dark-colored polymers and chelation of the Schiff base ${ }^{251}$ are responsible for a discoloration in pericarp of matured buckwheat achenes.

Fagopyrism, the photosensitization which occurs in animals fed on the grain with pericarp of buckwheat or on the whole plant,

20) P.O. Larsen, Acta Chem. Scand., 19, 1071 (1965).

21) C. S. Barnes and J. W. Loder, Aust. J. Chem., 15, 322 (1962).

22) S. Ishikawa, Sci. Reports Inst. Phys. Chem. Research (Tokyo), 38, 567, 574, 578 (1962).

23) A. Ohsuka, J. Chem. Soc. Japan, 83, 757 (1962).

24) S. Seto, K. Ozaki and H. Horiuchi, J. Chem. Soc., Japan (Ind. Chem. Soc.), 57, 687 (1954); S. Takahashi and S. Seto, ibid., 58, 796 (1955).

25) M. Yamaguchi, J. Chem. Soc. Japan, 74, 272 (1953). 
especially, of the flowering stage, is recognized nitrogen containing unknown groups. ${ }^{281}$ some years ago. ${ }^{26,27)}$ According to H. Brock- Looking over speculatively, it might be mann, one of the photodynamic substances attractive to investigate the relationship responsible for the disease is fagopyrin which between fragopyrin and the hydroxybenzylis a derivative of hypericin substituted by amines in buckwheat.

26) I. Yumino, Jap. J. of Dermat., 55, 144 (1944).

27) N. Y. Clare, Advan. Vet. Sci., 2, 182 (1955).

28) H. Brockman, Progr, Chem. Org. Nat. Prod., 14, 141 (1957). 